\title{
Eupafolin and Ethyl Acetate Fraction of Kalanchoe gracilis Stem Extract Show Potent Antiviral Activities against Enterovirus 71 and Coxsackievirus A16
}

\author{
Ching-Ying Wang, ${ }^{1,2}$ Shun-Chueh Huang, ${ }^{3}$ Zhen-Rung Lai, ${ }^{3,4}$ Yu-Ling Ho, ${ }^{4}$ Yu-Jen Jou, ${ }^{2,5}$ \\ Szu-Hao Kung, ${ }^{6}$ Yongjun Zhang, ${ }^{7}$ Yuan-Shiun Chang, ${ }^{1}$ and Cheng-Wen Lin ${ }^{2,8}$ \\ ${ }^{1}$ School of Chinese Pharmaceutical Sciences and Chinese Medicine Resources, China Medical University, Taichung 404, Taiwan \\ ${ }^{2}$ Department of Medical Laboratory Science and Biotechnology, China Medical University, Taichung 404, Taiwan \\ ${ }^{3}$ School of Pharmacy, China Medical University, Taichung 404, Taiwan \\ ${ }^{4}$ Department of Nursing, Hungkuang University, Taichung 433, Taiwan \\ ${ }^{5}$ Institute of Biochemistry, National Chung Hsing University, Taichung 402, Taiwan \\ ${ }^{6}$ Department of Biotechnology and Laboratory Science in Medicine, National Yang Ming University, Taipei 112, Taiwan \\ ${ }^{7}$ Fujian Center for Disease Control and Prevention, Fuzhou, Fujian 350001, China \\ ${ }^{8}$ Department of Biotechnology, Asia University, Wufeng, Taichung 413, Taiwan
}

Correspondence should be addressed to Yuan-Shiun Chang; yschang@mail.cmu.edu.tw and Cheng-Wen Lin; cwlin@mail.cmu.edu.tw

Received 17 April 2013; Accepted 24 July 2013

Academic Editor: Shun-Wan Chan

Copyright (c) 2013 Ching-Ying Wang et al. This is an open access article distributed under the Creative Commons Attribution License, which permits unrestricted use, distribution, and reproduction in any medium, provided the original work is properly cited.

\begin{abstract}
Enterovirus 71 (EV71) and coxsackievirus A16 (CoxA16) are main pathogens of hand-foot-and-mouth disease, occasionally causing aseptic meningitis and encephalitis in tropical and subtropical regions. Kalanchoe gracilis, Da-Huan-Hun, is a Chinese folk medicine for treating pain and inflammation, exhibiting antioxidant and anti-inflammatory activities. Our prior report (2012) cited K. gracilis leaf extract as moderately active against EV71 and CoxA16. This study further rates antienteroviral potential of K. gracilis stem (KGS) extract to identify potent antiviral fractions and components. The extract moderately inhibits viral cytopathicity and virus yield, as well as in vitro replication of EV71 $\left(\mathrm{IC}_{50}=75.18 \mu \mathrm{g} / \mathrm{mL}\right)$ and CoxA16 $\left(\mathrm{IC}_{50}=81.41 \mu \mathrm{g} / \mathrm{mL}\right)$. Ethyl acetate (EA) fraction of KGS extract showed greater antiviral activity than that of $n$-butanol or aqueous fraction: $\mathrm{IC}_{50}$ values of $4.21 \mu \mathrm{g} / \mathrm{mL}$ against EV71 and $9.08 \mu \mathrm{g} / \mathrm{mL}$ against CoxA16. HPLC analysis, UV-Vis absorption spectroscopy, and plaque reduction assay indicate that eupafolin is a vital component of EA fraction showing potent activity against EV71 $\left(\mathrm{IC}_{50}=1.39 \mu \mathrm{M}\right)$ and $\mathrm{CoxA16}\left(\mathrm{IC}_{50}=5.24 \mu \mathrm{M}\right)$. Eupafolin specifically lessened virus-induced upregulation of IL- 6 and RANTES by inhibiting virus-induced ERK1/2, AP-1, and STAT3 signals. Anti-enteroviral potency of KGS EA fraction and eupafolin shows the clinical potential against EV71 and CoxA16 infection.
\end{abstract}

\section{Introduction}

Enteroviruses (EVs) like polio, enterovirus 71 (EV71), and coxsackieviruses A (CoxA) belong to the Picornaviridae family, causing severe manifestations: for example, hand, foot, and mouth disease (HFMD); meningitis; encephalitis; flaccid paralysis; myocarditis [1-3]. EV consists of singlestrand, positive-sense RNA approximately $7.4 \mathrm{~kb}$ in size and a nonenveloped capsid (27-30 nm in diameter). Viral genome has a long open reading frame encoding polyprotein cleaved to form four structural proteins (VP1, VP2, VP3, and VP4) and seven nonstructural proteins $(2 \mathrm{~A}-\mathrm{C}, 3 \mathrm{~A}-\mathrm{D})$ by proteases $2 \mathrm{~A}^{\text {pro }}$ and $3 \mathrm{C}^{\text {pro }}[2,4]$. EV71 and CoxA16 are two major causative agents of HFMD in children with severe brain stem encephalitis [5]. Several EV71 outbreaks with severe or even fatal cases occurred in Malaysia in 1997, Taiwan in 1998, Japan in 2000, Vietnam in 2005, and Singapore in 2008. Recent mixed infection of EV71 and CoxA16 in HFMD cases appeared in China and India during 2009-2010 [5-7]. No vaccine or antiviral agent for EV infection is currently available. 


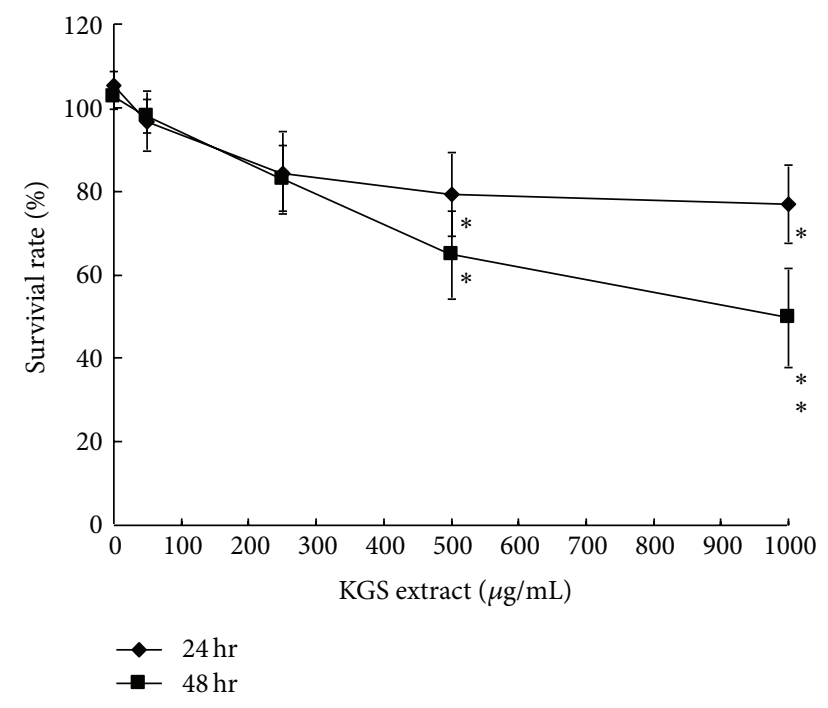

FIGURE 1: Survival rate of RD cells treated with KGS extract. $\mathrm{RD}$ cells cultured on 96-well plates were treated with indicated concentrations of KGS extract, then incubated for 24 or 48 hours, followed by MTT assay. Survival rates of cells were calculated as the ratio of $\mathrm{OD}_{570-630 \mathrm{~nm}}$ of treated cells to $\mathrm{OD}_{570-630 \mathrm{~nm}}$ of untreated cells. ${ }^{*} P$ value $<0.05$ by Scheffe's test.

Kalanchoe gracilis (L.), a.k.a. Da-Huan-Hun, is a Chinese folk medicine in Taiwan, commonly used to alleviate pain, fever, inflammation, and injuries [8-10]. Its bioactive compounds include coumarin, bufadienolides, flavonoids (quercetin, kaempferol, teolin, quercitrin, and eupafolin), and glycosidic derivatives of eupafolin demonstrating antioxidant, anti-inflammatory, and/or antiproliferative activities [11-13]. K. gracilis leaf extract with ferulic acid, quercetin, and kaempferol shows moderately antiviral activity against CoxA16 and EV71 in vitro and in vivo [14]. K. gracilis stem extract exhibits potent analgesic and anti-inflammatory activities in acetic acid-induced writhing responses, elevating superoxide dismutase activities in the liver and reducing TNF-alpha levels of inflamed animal model tissues [9]. Methanolic extract of $K$. gracilis stem has potent antioxidant, anti-inflammation, and antiproliferative activities in vitro [10]. Eupafolin (6-methoxyluteolin), identified in the stem of K. gracilis, significantly reduces nitric oxide (NO) production and expressions of inducible nitric oxide synthase (iNOS) and cyclooxygenase-2 (COX-2) in LPS-treated RAW264.7 macrophage cells [10]. Eupafolin is the crucial and bioactive component of antioxidant, anti-inflammatory, and antiproliferative activities in many medicinal herbs: for example, Artemisia princeps, Eupatorium perfoliatum L., and Gaillardia aristata Pursh [11-13, 15].

This study investigated antiviral effects of $K$. gracilis stem (KGS) extract, ethyl acetate (EA), and $n$-butanol (BuOH) fractions against EV71 and CoxA16, ferreting out potential antiviral compounds of $K$. gracilis stem extract. EA fraction, better than $\mathrm{BuOH}$ fraction, effectively inhibited virusinduced cytopathicity and viral replication in vitro. Eupafolin, rich in EA fraction, showed a potent antiviral activity, with IC $_{50}$ values of less than $10 \mu \mathrm{M}$, inhibiting production of proinflammatory cytokines via suppressing ERK1/2 and AP-1 mediated signaling pathways.

\section{Materials and Methods}

2.1. Fractionation of K. gracilis Stem (KGS) Extract. K. gracilis was collected from farmlands and gardens in Chiayi County, as detailed in our prior report [14]; its stem juice filtered by Whatman No. 1 paper, and then lyophilized in an IWAKI FDR-50P freeze dryer. Powder of stem extract was stored in sterile bottles at $-20^{\circ} \mathrm{C}$, dissolved in distilled deionised water, then partitioned with ethyl acetate $(V / V=1 / 1)$. Water fraction was mixed with $n$-butanol $(V / V=1 / 1)$, with ethyl acetate (EA), $n$-butanol $(\mathrm{BuOH})$, and aqueous $\left(\mathrm{H}_{2} \mathrm{O}\right)$ fractions evaporated under reduced pressure by BUCHI Rotavapor R-114.

2.2. Viruses and Cells. EV71 and CoxA16 strains were amplified in $\mathrm{RD}$ cells grown in Dulbecco's Modified Eagle's Medium with $10 \%$ fetal bovine serum (FBS) at $37^{\circ} \mathrm{C}, 5 \% \mathrm{CO}_{2}$, as detailed in our prior report [14]. HeLa-G2AwtR cells were maintained in Modified Eagle's Medium with 10\% FBS and $20 \mu \mathrm{g} / \mathrm{mL}$ zeocin, expressing FRET probe as well as fusion protein of red fluorescent protein (DsRed)-2Apro cleavage motif-green fluorescent protein (GFP) [16].

2.3. Cell Viability Assay. In all, $3 \times 10^{4} \mathrm{RD}$ cells were added to each well of 96 -well plates, cultured at $37^{\circ} \mathrm{C}, 5 \% \mathrm{CO}_{2}$ overnight, then quintuplicate treated with KGS extract, indicated fraction (EA, $\mathrm{BuOH}$, or $\mathrm{H}_{2} \mathrm{O}$ ), eupafolin or caffeic acid for an additional 48-hour incubation. Cell survival

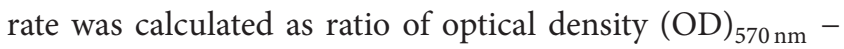
$\mathrm{OD}_{630 \mathrm{~nm}}\left(\mathrm{OD}_{570-630}\right)$ of treated cells to $\mathrm{OD}_{570-630}$ of mock cell using MTT assay [14]. Data showed means \pm SD from three independent experiments; $50 \%$ cytotoxic concentration $\left(\mathrm{CC}_{50}\right)$ yielding $50 \%$ toxic effect was determined via computer program (provided by John Spouge, National Center for Biotechnology Information, National Institutes of Health).

2.4. Cytopathic Effect (CPE) Reduction and Virus Yield. RD cells cultured in 6-well plates were infected with EV71 or CoxA16 at multiplicity of infection (MOI) 0.1 in the presence or absence of various amounts of KGS extract, indicated fraction, eupafolin or caffeic acid for 24 or 48 hours. Cellular morphology was observed and photographed under microscope. To quantify virus yield, cultured supernatants from each treated/infected cells were harvested 12, 24, 36, or 48 hours postinfection, then counted by real-time RT-PCR with VP1-specific primers, as described in our prior report [14]. The Ct value for viral yield in cultured supernatant was monitored by ABI PRISM 7000 sequence detection system (Applied Biosystems), delta Ct value calculated by subtracting Ct value for viral yield in cultured supernatant of infected cells with indicated treatment from that of cultured media of infected cells without treatment.

2.5. Plaque Reduction Assay. Monolayer of RD cells cultured in 6-well plates was infected with EV71 or CoxA16 (50 pfu per well) in the presence or absence of KGS extract $(1,10,50,100$, 

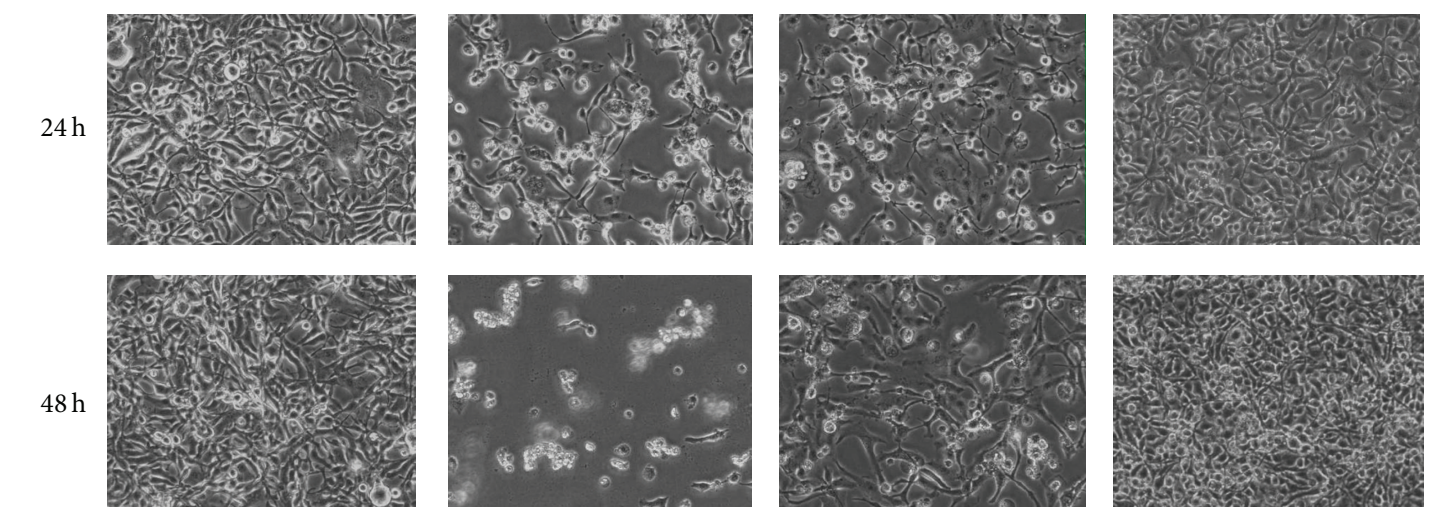

EV71

KGS extract

$(200 \mu \mathrm{g} / \mathrm{mL})$

(a)
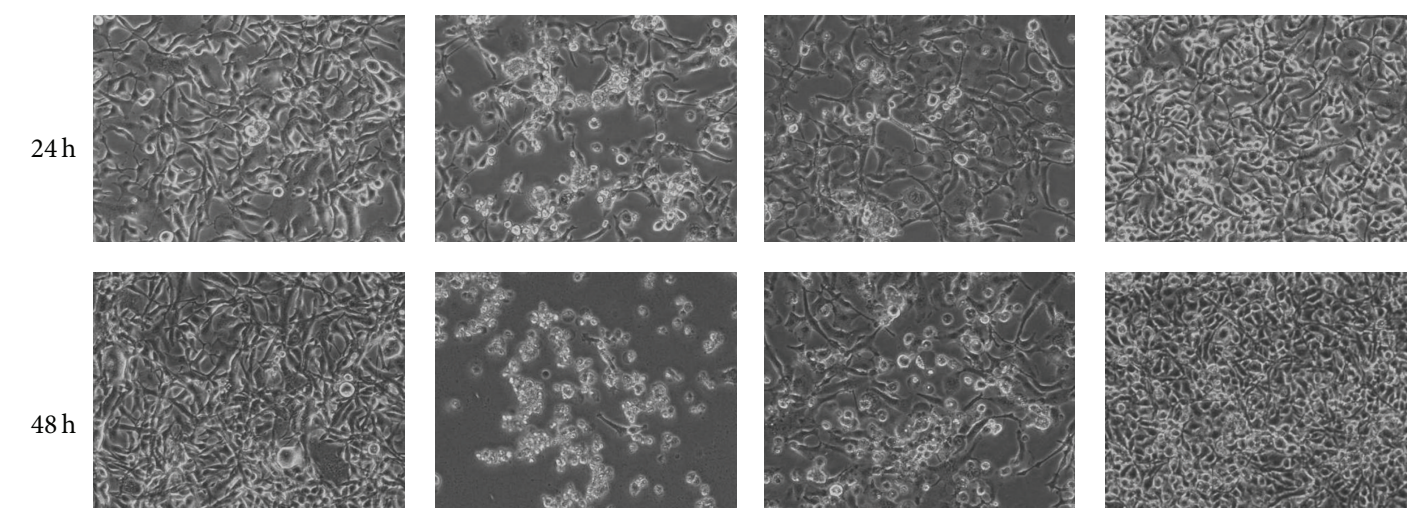

CoxA16

KGS extract

$(200 \mu \mathrm{g} / \mathrm{mL})$

(b)

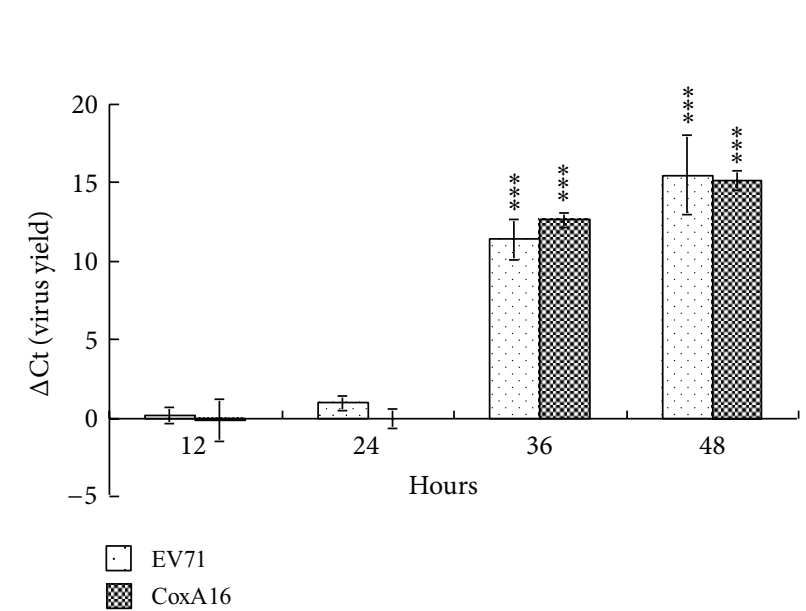

(c)

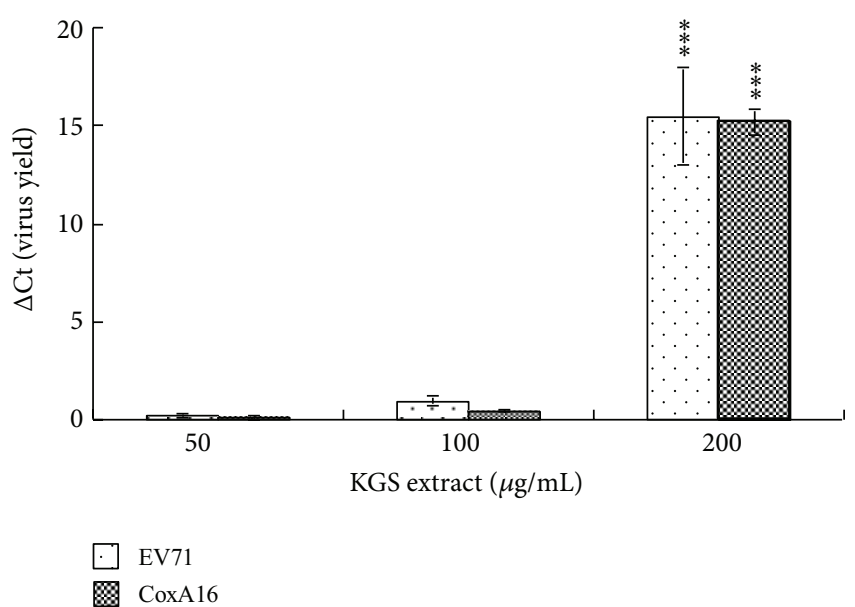

(d)

FIGURE 2: Inhibitory effects of KGS extract on viral cytopathicity and yield in RD cells. EV71 or CoxA16 at MOI of 0.1 mixed with indicated KGS extract concentration was immediately added to RD cell culture. Virus-induced cytopathic effect was photographed $36 \mathrm{~h}$ postinfection by reverse-phase microscopy $((a),(b))$. Virus yield in each cultured supernatant was measured by real-time RT-PCR in time(c) or concentration- (d) dependent manner. Delta Ct value was calculated by subtracting Ct value for viral load in cultured supernatant of KGS extract-treated infected cells from Ct value for viral load in cultured supernatant of infected cells without treatment. ${ }^{* * *} P$ value $<0.001$ by Scheffe's test. 
TABLE 1: Cytotoxicity and antienteroviral activity of KGS extract, fractions, and marker components.

\begin{tabular}{|c|c|c|c|c|c|}
\hline & \multirow[b]{2}{*}{$\mathrm{CC}_{50}(\mu \mathrm{g} / \mathrm{mL})$ to $\mathrm{RD}$ cells } & \multicolumn{2}{|c|}{ EV71 } & \multicolumn{2}{|c|}{ COXA16 } \\
\hline & & $\mathrm{IC}_{50}(\mu \mathrm{g} / \mathrm{mL})$ & SI & $\mathrm{IC}_{50}(\mu \mathrm{g} / \mathrm{mL})$ & SI \\
\hline KGS extract & 1622.30 & 75.18 & 21.58 & 81.41 & 19.93 \\
\hline EA fraction & 409.83 & 4.21 & 97.35 & 9.08 & 45.14 \\
\hline $\mathrm{BuOH}$ fraction & 425.53 & 11.88 & 35.82 & 18.23 & 23.34 \\
\hline $\mathrm{H}_{2} \mathrm{O}$ fraction & $>500$ & $>100$ & & $>100$ & \\
\hline Eupafolin & 355.87 & 0.44 & 808.80 & 1.66 & 214.38 \\
\hline Caffeic acid & 274.72 & 23.87 & 11.51 & 35.51 & 7.74 \\
\hline
\end{tabular}

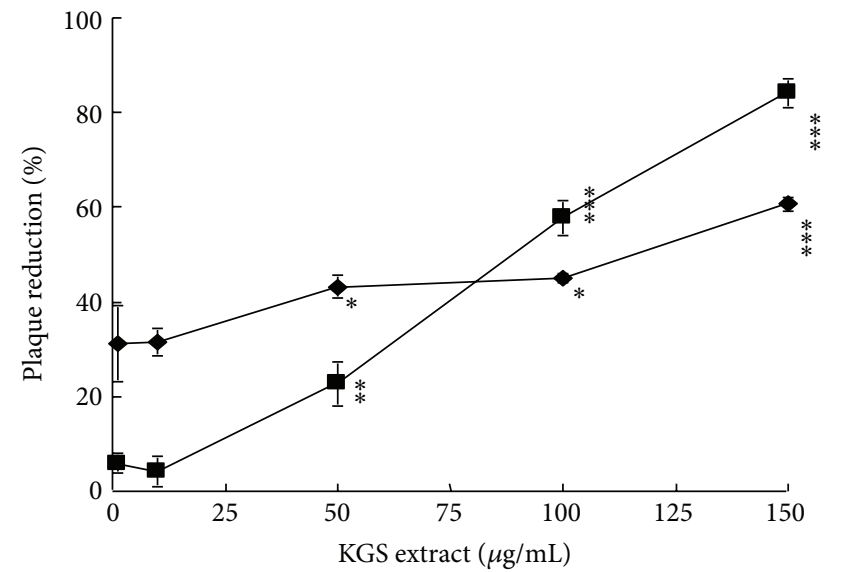

$\longrightarrow$ EV71
$\rightarrow$ CoxA16

FIgURE 3: Plaque reduction by KGS extract. Monolayer of RD cells on six-well plates infected with EV71 or CVA16 at a titer of $100 \mathrm{pfu}$ was treated simultaneously with indicated KGS extract concentrations. After $1 \mathrm{~h}$ incubation, monolayer was covered with $2 \mathrm{~mL}$ of agarose overlay medium and incubated for 2 days at $37^{\circ} \mathrm{C}$ in a $\mathrm{CO}_{2}$ incubator. Finally, plaques were counted after crystal violet staining.

$150 \mu \mathrm{g} / \mathrm{mL})$, indicated fraction $(0.5,1,5,10,20 \mu \mathrm{g} / \mathrm{mL})$, and eupafolin or caffeic acid $(0.1,1,5,10,20,50 \mu \mathrm{g} / \mathrm{mL})$ for $1 \mathrm{~h}$ in a $37^{\circ} \mathrm{C}, 5 \% \mathrm{CO}_{2}$ incubator. Medium containing 3\% agarose ( $2 \mathrm{~mL}$ per well) was used to cover cell monolayer. After 2 -day incubation at $37^{\circ} \mathrm{C}$ in a $\mathrm{CO}_{2}$ incubator, cell monolayer was stained with $0.1 \%$ Crystal Violet and plaque number further counted. Fifty percent (50\%) inhibitory concentration $\left(\mathrm{IC}_{50}\right)$ reducing number of plaques by $50 \%$ was calculated by computer program, selectivity index (SI) derived by ratio of $\mathrm{CC}_{50}$ to $\mathrm{IC}_{50}$. Data presented are mean values of three independent experiments; error bars represent standard deviations.

2.6. Cell Cycle Analysis Using Flow Cytometry. A total of $2 \times$ $10^{5} \mathrm{RD}$ cells were infected with EV71 or CoxA16 at MOI of 0.5 in the presence and absence of $10 \mu \mathrm{g} / \mathrm{mL}$ EA or $\mathrm{BuOH}$ fraction, then collected $36 \mathrm{~h}$ postinfection, and washed with PBS buffer. After centrifuging at $8000 \mathrm{rpm}$ for $3 \mathrm{~min}$, cell pellet dissolved with $100 \mu \mathrm{L}$ PBS buffer was incubated $1 \mathrm{~mL}$ of $70 \%$ alcohol in $-20^{\circ} \mathrm{C}$ overnight and washed twice with PBS buffer for propidium iodide (PI) staining (Biolegend).
After $30 \mathrm{~min}$ incubation with PI/RNAase solution, over 10,000 stained cells were analyzed by BD FACSAria (Becton Dickinson) with excitation at $488 \mathrm{~nm}$ and emission at $633 \mathrm{~nm}$.

2.7. Fingerprint Analysis by HPLC. Marker compounds of K. gracilis (ferulic acid, quercetin, kameperfol, eupafolin, and caffeic acid) were obtained from ChromaDex, Inc. and Sigma-Aldrich Chemical Co. Fingerprint profiles of KGS $\mathrm{EA}$ and $\mathrm{BuOH}$ fractions were analyzed and compared with retention time of marker compounds, using Waters 2695 Separations Module in the HPLC instrument (Waters 2695 Separations Module, Waters 2996 Photodiode Array Detector, Atlantis dC18 $5 \mu \mathrm{m} 4.6 \times 250 \mathrm{~mm}$ column). Mobile phase was $0.2 \%$ formic acid and acetonitrile $(70: 30)$, chromatographic separation set at $1.0 \mathrm{~mL} / \mathrm{min}$ flow rate, and elution peaks detected at $345 \mathrm{~nm}$ with a $2996 \mathrm{PDA}$ detector.

2.8. Virucidal and Virus Attachment Assays. For virucidal assay, EV71 or CoxA16 ( $\left.10^{6} \mathrm{pfu}\right)$ was incubated with EA, $\mathrm{BuOH}$ fraction $(10,100 \mu \mathrm{g} / \mathrm{mL})$, or eupafolin $(1,10 \mu \mathrm{g} / \mathrm{mL})$ for $1 \mathrm{~h}$ at $4^{\circ} \mathrm{C}$. Mixture was further diluted by 100 - and 1000 fold, infectious activity performed by plaque assay. For virus attachment assay, EV71 or CoxA16 (50 pfu) was added to the $\mathrm{RD}$ cell monolayer in 6-well plates, concomitant with EA, $\mathrm{BuOH}$ fraction, or eupafolin. After $1 \mathrm{~h}$ incubation at $4^{\circ} \mathrm{C}$, cell monolayer was washed twice with PBS, then overlaid with $2 \mathrm{~mL}$ of culture medium containing 3\% agarose for 2 days at $37^{\circ} \mathrm{C}$ in a $\mathrm{CO}_{2}$ incubator. Virus attachment activity was calculated as residual plaques after staining with $0.1 \%$ crystal violet solution.

2.9. 2A Protease Activity Assay Using FRET. HeLa-G2AwtR cells expressed fusion substrates as FRET probes containing $2 \mathrm{~A}$ protease specific cleavage peptides at the middle region. Cells seeded into the 6-well tissue culture plates were infected with EV71 or CoxA16 at MOI of 1 in the presence or absence of $10 \mu \mathrm{g} / \mathrm{mL}$ of EA or $\mathrm{BuOH}$ fraction and $1 \mu \mathrm{g} / \mathrm{mL}$ eupafolin. Two days postinfection, cells were harvested, and then fluorescent intensity of the FRET probes in lysates was determined by fluorescent-plate reader with excitation wavelength at $390 / 20 \mathrm{~nm}$ (for $\mathrm{GFP}^{2}$ ) and emission wavelength at 590/14 nm (for DsRed2), in which DsRed2 was excited by emission wavelength of $\mathrm{GFP}^{2}$ at 510/10 nm. EV71 and CoxA16 infection substantially abrogated FRET; treatment with $2 \mathrm{~A}$ protease inhibitors will restore FRET. 


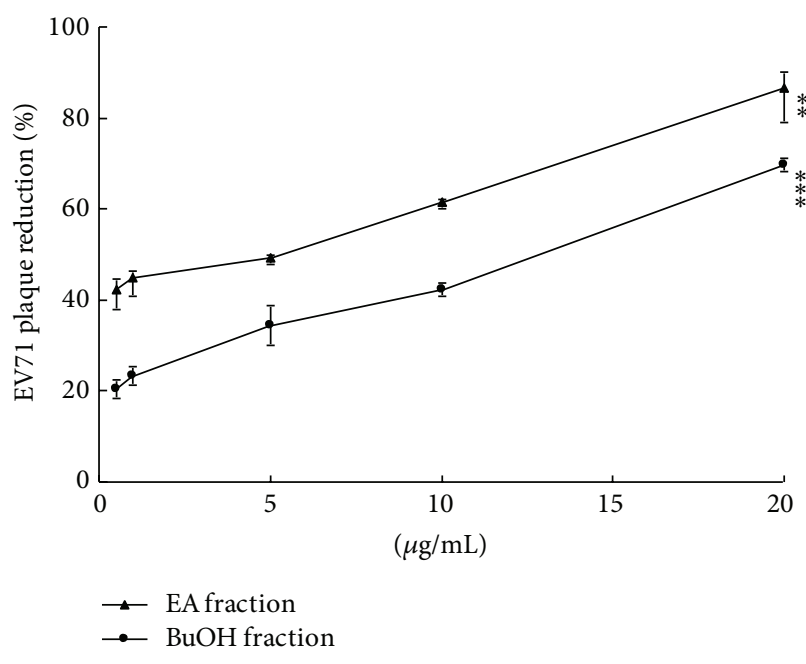

(a)

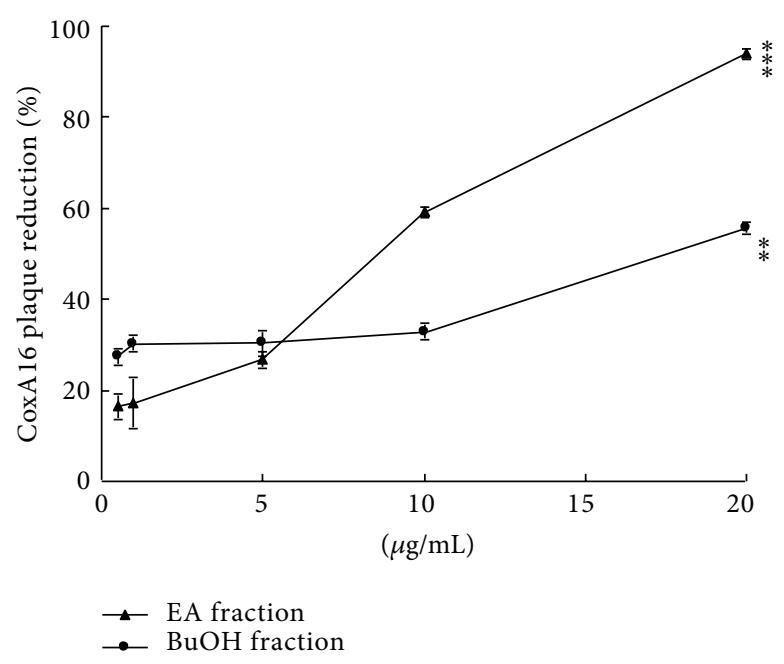

(b)

Figure 4: Plaque reduction by EA and $\mathrm{BuOH}$ fractions of KGS extract. Lyophilized KGS extract powder was dissolved in water, then fractionated by ethyl acetate (EA), followed by $n$-butanol $(\mathrm{BuOH})$. Each fraction was plaque assayed for antiviral activity against EV71 (a) and CoxA16 (b).

2.10. Quantification of RANTES and IL-6 Gene Expression Using Real-Time RT-PCR. Total RNA was isolated from virus-infected $\mathrm{RD}$ cells treated with interferon- (IFN-) $\alpha$, EA fraction, or eupafolin by purification kit (PureLink. TM. Micro-to-Midi. TM. total. RNA purification system, Invitrogen) used for cDNA synthesis with oligo dT primer and SuperScript III reverse transcriptase kit (Invitrogen). To gauge mRNA expression in response to EA fraction or eupafolin treatment and/or virus infection, two-step RTPCR with SYBR Green I was used. Oligonucleotide primer pairs included $5^{\prime}$-TCCCCATATTCCTCGGAC- $3^{\prime}$ and $5^{\prime}-$ GATGTACTCCCGAACCCA-3' for human RANTES, $5^{\prime}$ GATGGATGCTTCCAATCTGGAT-3' and $5^{\prime}$-AGTTCTCCATAGAGAACAACATA- $3^{\prime}$ for IL-6, and $5^{\prime}$-AGCCACATCGCTCAGACAC- $3^{\prime}$ and $5^{\prime}$-GCCCCAATACGACCAAATCC-3' for GAPDH. Real-time PCR reaction was carried out using ABI PRISM 7700 sequence detection system, as described in prior study [14]. Relative mRNA expression levels of indicated were normalized by housekeeping gene GAPDH.

2.11. Western Blot Analysis. Lysates from virus-infected RD cells treated with interferon-alpha, EA fraction, or eupafolin were dissolved in SDS-PAGE sample buffer with 2-mercaptoethanol, boiled for $10 \mathrm{~min}$, then applied to run $8 \%$ SDSPAGE gels. After transfer, resulting blots were blocked with 5\% skim milk in TBST, incubated with antiphospho-STAT3 (Tyr705), antiphospho-ERK1/2, antiphospho-p38 MAPK, antiphospho-p65 (NF- $\kappa \mathrm{B})$, antiphospho-c-Jun, or anti- $\beta$ actin antibodies (Cell Signaling Technology), respectively. Immunoreactive bands were developed by horseradish peroxidase-conjugated secondary antibodies and enhanced chemiluminescent substrates (Amersham Pharmacia Biotech).
2.12. In Vivo Anti-EV71 Assay. The 1-day-old suckling mice were intraperitoneally infected with $1.7 \times 10^{7} \mathrm{pfu}$ EV71 then intraperitoneally injected with $K$. gracilis stem extract $(5 \mathrm{mg} / \mathrm{kg}$ ) once on days $1,3,5$, and 7 . Three mice from each group were sacrificed on days 2, 4, 6, and 8; their intestine samples were collected for detection of virus loads using realtime RT PCR, described as in Section 2.4.

2.13. Statistical Analysis. Data from three independent experiments were represented as mean \pm standard deviation (SD) and statistically analyzed, using SPSS program (version 10.1, SPSS Inc., IL) via one-way ANOVA analysis by Scheffe's test.

\section{Results}

3.1. Antiviral Activity of KGS Extract against EV71 and CoxA16. KGS extract has a $\mathrm{CC}_{50}$ value of $1622 \mu \mathrm{g} / \mathrm{mL}$ to RD cells $48 \mathrm{~h}$ posttreatment, showing low cytotoxicity (Figure 1, Table 1). Subsequently, antienterovirus ability of KGS extract was rated with cytopathicity, virus yield, and plaque reduction assays. KGS extract $(200 \mu \mathrm{g} / \mathrm{mL})$ reduced cytopathicity of RD cells induced by EV71 and CoxA16 (Figures 2(a)-2(b)). Virus titer assay of cultured supernatants using real-time RT PCR assay indicated KGS extract in vitro significantly inhibiting EV71 and CoxA16 replication in both time- and concentration-dependent manner (Figures 2(c)-2(d)). For determining potency and selectivity, plaque reduction assay was further performed (Figure 3), revealing $\mathrm{IC}_{50}$ values of KGS extract as $75.18 \mu \mathrm{g} / \mathrm{mL}$ and $81.41 \mu \mathrm{g} / \mathrm{mL}$ for EV71 and CoxA16, respectively. Meanwhile, selectivity index (SI) of KGS extract was approximately 20 (Table 1). Antiviral activity of KGS extract in 1-day suckling mice was also examined in viral loads by real-time PCR (see Supplementary Material, Supplemental Table 1, available online at 

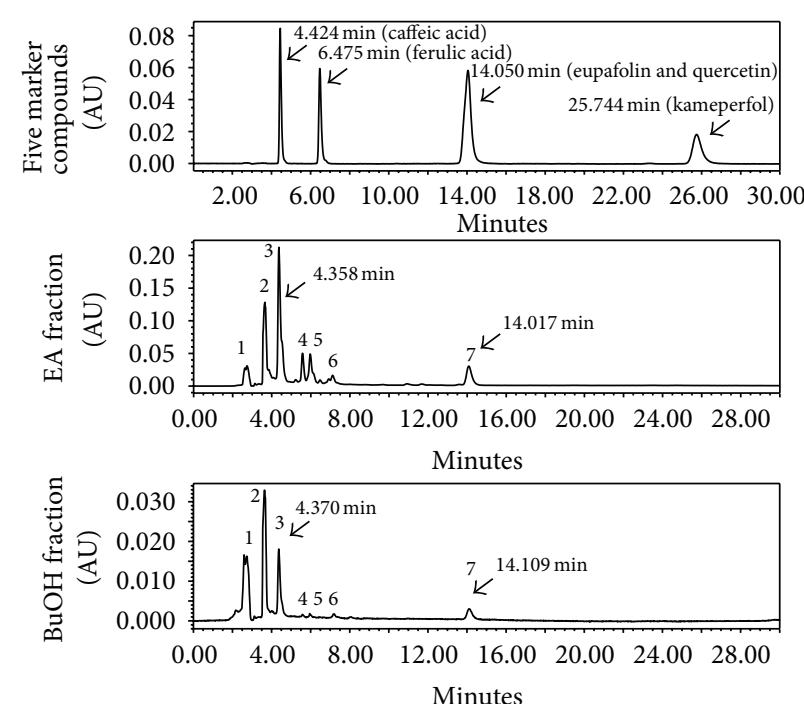

(a)
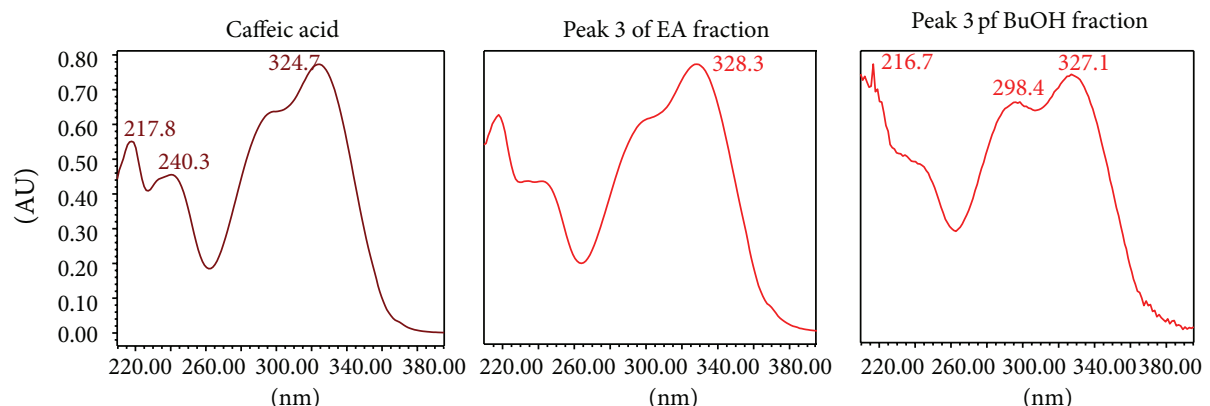

(b)
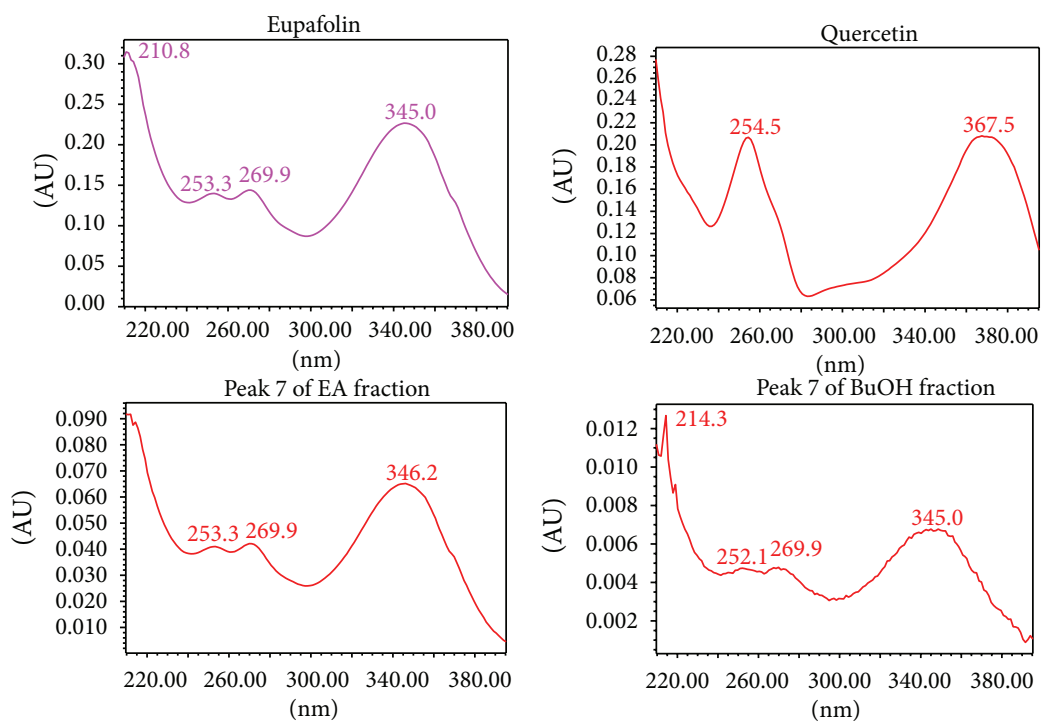

(c)

FIGURE 5: HPLC fingerprint profiles and UV/Vis absorption spectra of EA and BoOH fractions. Marker components (caffeic acid, ferulic acid, quercetin, eupafolin, and kaempferol), as well as both fractions of KGS extract, were analyzed by HPLC with C-18 reverse phase column, eluents detected at $345 \mathrm{~nm}$ with a 2996 PDA detector (a). Maximum absorption wavelengths of caffeic acid, quercetin, eupafolin, and chromatographic peaks 3 and 7 were measured by UV/Vis absorption spectra (200-360 nm) ((b), (c)). 


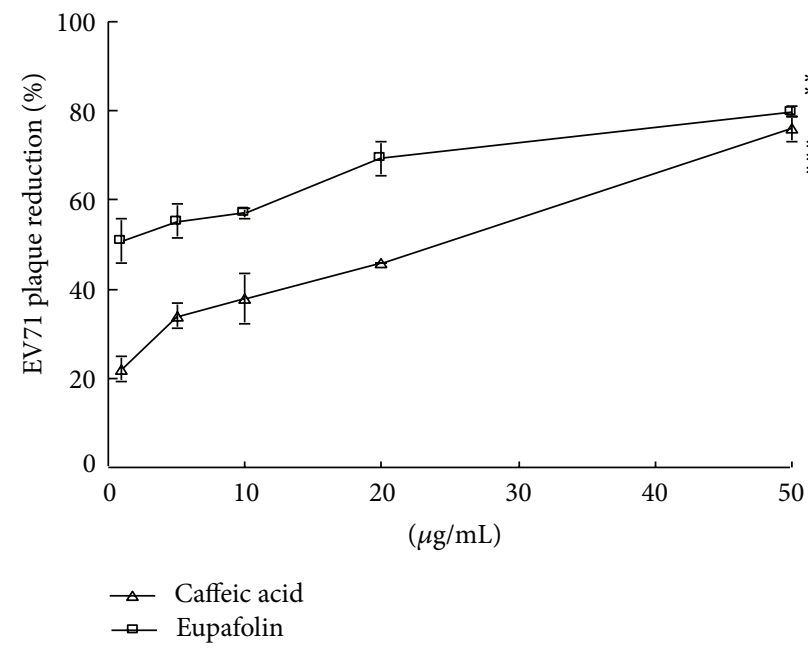

(a)

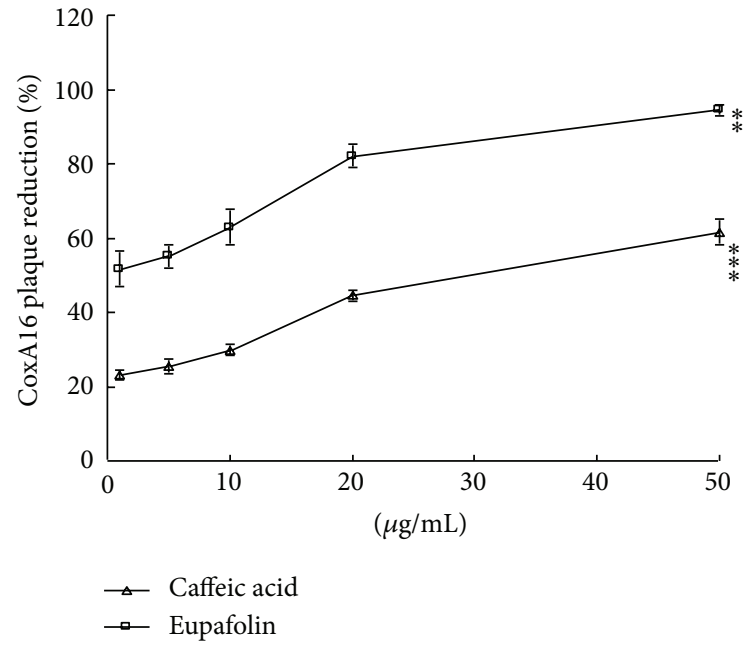

(b)

FIGURE 6: Plaque reduction by marker components: caffeic acid and eupafolin. Caffeic acid and eupafolin were analyzed for antiviral activity against EV71 (a) and CoxA16 (b), using plaque assay.

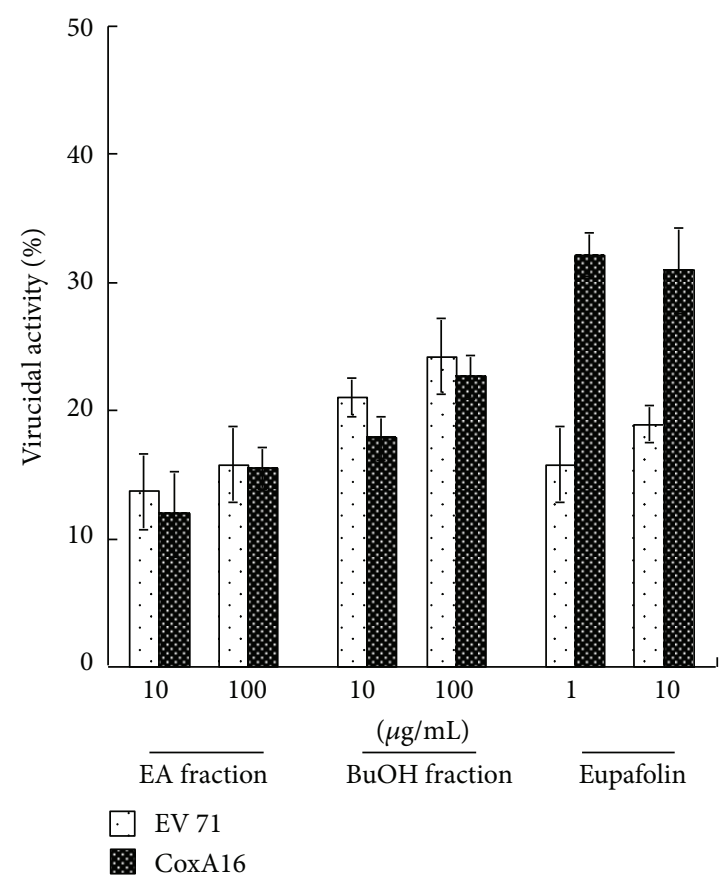

(a)

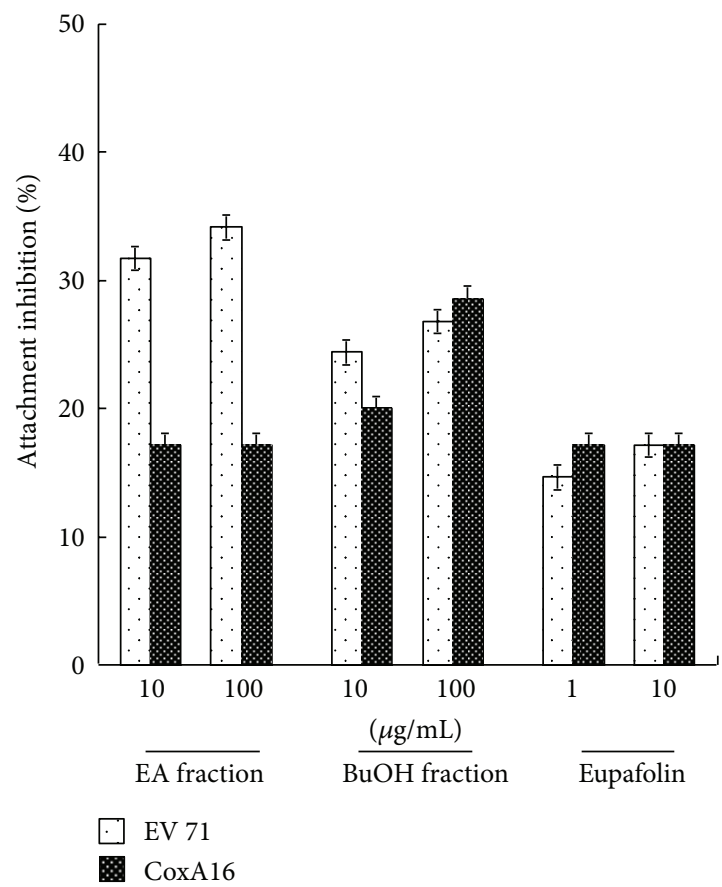

(b)

FIGURE 7: Virucidal activity and attachment inhibition of eupafolin, EA, and BuOH fractions. In virucidal assay (a), eupafolin or each fraction was mixed with EV71 or CoxA16 $\left(10^{6} \mathrm{pfu}\right)$, then incubated at $4^{\circ} \mathrm{C}$ for $1 \mathrm{~h}$. Residual infectivity was performed by plaque assay with 1000 -fold dilution of virus/compound mixture. In the attachment assay (b), EV71 or CoxA16 (50 pfu) was mixed with EA, BuOH fraction, or eupafolin, then immediately added onto RD cell monolayer for $1 \mathrm{~h}$ at $4^{\circ} \mathrm{C}$. After washing twice with PBS, monolayer was overlaid with $2 \mathrm{~mL}$ of agarose medium for 2 days at $37^{\circ} \mathrm{C}$ in $\mathrm{CO}_{2}$ incubator. Attachment inhibition was calculated as residual plaques after crystal violet staining.

http://dx.doi.org/10.1155/2013/591354). In mock group, EV71 in intestine samples was detectable 2, 4, and 6 days postintraperitoneal inoculation. By contrast, intraperitoneal treatment with KGS extract resulted in the decrease of EV71 loads compared to the mock group 2 days postinoculation, as not detectable 4 , and 6 days postinoculation. Results demonstrate KGS extract consisting of active anti-EV71 and CoxA16 components in vitro and in vivo.

3.2. Functional Fractions of KGS Extract against EV71 and CoxA16. To evaluate potential antiviral fractions, KGS extract was further fractionated sequentially with $\mathrm{EA}, \mathrm{BuOH}$, 

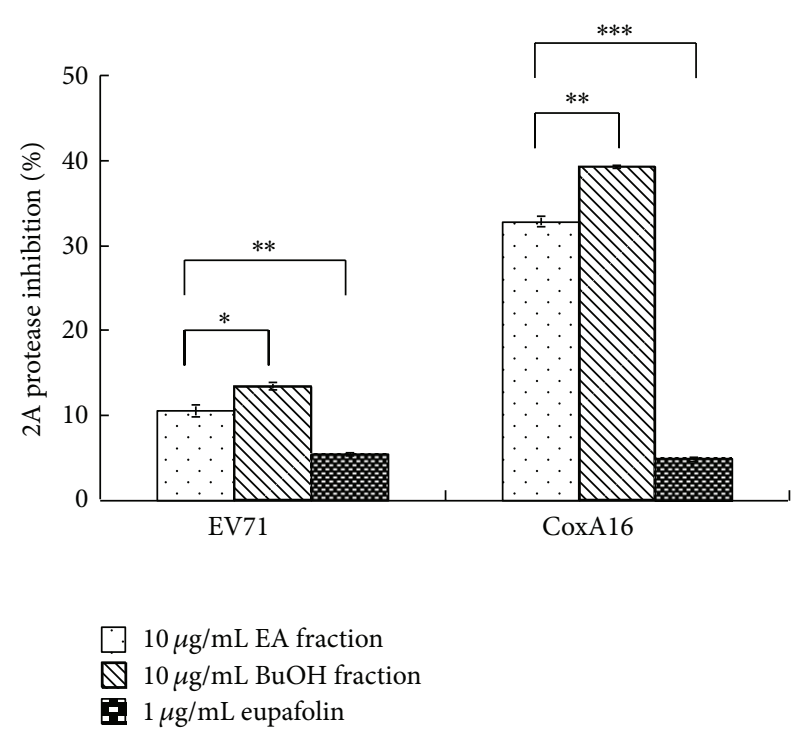

FIGURE 8: Inhibitory effect of eupafolin, EA, and $\mathrm{BuOH}$ fractions on viral $2 \mathrm{~A}$ protease activity in cell-based FRET assay. HeLa-G2AwtR cells expressed 2A-cleavage motif in FRET probes were infected with EV71 or CVA16 at a MOI of 1, coexistent with treatment of eupafolin, $\mathrm{EA}$, and $\mathrm{BuOH}$ fractions. Cells harvested 48 postinfection were subjected to measurement by a fluorescent-plate reader with excitation wavelength at $390 / 20 \mathrm{~nm}$ and emission wavelength at $510 / 10 \mathrm{~nm}$ (for $\mathrm{GFP}^{2}$ ) or 590/14 $\mathrm{nm}$ (for DsRed2). Inhibitory activity was calculated as FRET ratio, that is, intensity of emission at $590 / 14 \mathrm{~nm}$ divided by that at $510 / 10 \mathrm{~nm} .{ }^{*} P$ value $<0.05$; ${ }^{* *} P$ value $<0.01 ;{ }^{* * *} P$ value $<0.001$ by Scheffe's test.

and water; lyophilized powder of these three fractions was subsequently used to examine cytotoxicity and apoptosis to $\mathrm{RD}$ cells and antiviral effects on virus yield and plaque reduction (Figures 3-4). MTT assay elicited $\mathrm{CC}_{50}$ values of KGS $\mathrm{EA}, \mathrm{BuOH}$, and $\mathrm{H}_{2} \mathrm{O}$ fractions above $400 \mu \mathrm{g} / \mathrm{mL}$ (Table 1 ), indicating these as less cytotoxic to $\mathrm{RD}$ cells. Plaque reduction assay indicated EA and $\mathrm{BuOH}$, but not $\mathrm{H}_{2} \mathrm{O}$ fraction, effectively inhibiting EV71 more than CoxA16 replication in vitro (Figures 4(a)-4(b), Table 1). Antienterovirus activity and selectivity of fractions in plaque reduction assay was ranked in the following order: $\mathrm{EA}\left(\mathrm{IC}_{50}=4.21 \sim 9.08 \mu \mathrm{g} / \mathrm{mL}\right.$; $\mathrm{SI}=45.14 \sim 97.35) \quad>\mathrm{BuOH} \quad\left(\mathrm{IC}_{50}=11.88 \sim 18.23 \mu \mathrm{g} / \mathrm{mL}\right.$; $\mathrm{SI}=23.34 \sim 35.82)>\mathrm{H}_{2} \mathrm{O}\left(\mathrm{IC}_{50}=>100 \mu \mathrm{g} / \mathrm{mL}\right)$ (Figures $4(\mathrm{a})$ 4(b), Table 1). Moreover, cell cycle analysis using flow cytometry indicated EV71 and CoxA16 infection causing significant increases of apoptosis (sub-G1 phase) in RD cells as well as EA and $\mathrm{BuOH}$ treatment markedly reducing the apoptosis from about $70 \%$ to near 20\% (Supplemental Figure 1). Results verify EA fraction exhibiting significantly higher antiviral activity against EV71 and CoxA16 than BuOH fraction, containing potential antienterovirus components.

3.3. Eupafolin as Potent Antiviral Component in KGS EA Fraction against EV71 and CoxA16. To examine fingerprint of KGS fractions, ferulic acid, quercetin, kaempferol, caffeic acid, and eupafulin served as standard marker components; $\mathrm{EA}$ and $\mathrm{BuOH}$ fractions were analyzed using HPLC with C-18 reverse phase column (Figure 5(a)). The retention time of
HLPC chromatograph at $345 \mathrm{~nm}$ was at $4.424 \mathrm{~min}$ for caffeic acid, $6.475 \mathrm{~min}$ for ferulic acid, $14.050 \mathrm{~min}$ for eupafolin (overlapped with quercetin), and $25.744 \mathrm{~min}$ for kameperfol, respectively. HPLC chromatogram indicated retention times of Peak 3 and Peak 7 of EA and $\mathrm{BuOH}$ fractions as consistent with caffeic acid and eupafolin (or quercetin), respectively. UV absorption spectra $(200-400 \mathrm{~nm})$ indicated Peak 3 as the similar profile to caffeic acid and Peak 7 as the same profile of eupafolin, not quercetin (Figures 5(b)-5(c)). HPLC chromatogram and UV absorption spectra demonstrated EA and $\mathrm{BuOH}$ fractions consisting of caffeic acid and eupafolin. Based on the calibration curve of standard markers, amount of eupafolin was $3.10 \pm 0.09 \mu \mathrm{g} / \mathrm{mg}$ in EA fraction and 0.32 $\pm 0.01 \mu \mathrm{g} / \mathrm{mg}$ in $\mathrm{BuOH}$ fraction, respectively. The amounts of caffeic acid in EA and BuOH fraction were $10.91 \pm 0.34 \mu \mathrm{g} / \mathrm{mg}$ and $0.80 \pm 0.02 \mu \mathrm{g} / \mathrm{mg}$, respectively. Higher amounts of caffeic acid and eupafolin could account for better antienterovirus activity of EA versus $\mathrm{BuOH}$ fraction. Subsequently, antiviral activity of caffeic acid and eupafolin against EV71 and CoxA16 were rated by plaque reduction assay (Figure 6). Eupafolin had potent antiviral activity, with $\mathrm{IC}_{50}$ values of $0.44 \mu \mathrm{g} / \mathrm{mL}(1.39 \mu \mathrm{M})$ for EV71 and $1.66 \mu \mathrm{g} / \mathrm{mL}(5.24 \mu \mathrm{M})$ for CoxA16, showing excellent selectivity with SI values of 808.80 for EV71 and 214.38 for CoxA16 (Figure 6, Table 1). Meanwhile, $\mathrm{IC}_{50}$ values of caffeic acid were $23.87 \mu \mathrm{g} / \mathrm{mL}$ for EV71 and $35.51 \mu \mathrm{g} / \mathrm{mL}$ for CoxA16. Caffeic acid showed less antiviral activity than eupafolin, which indicated eupafolin playing a key role in anti-EV71 and CoxA16 actions of KGS EA fraction.

3.4. Virucidal Activity by Eupafolin. To evaluate possible direct-acting antiviral mechanism, eupafolin, $\mathrm{EA}$, and $\mathrm{BuOH}$ fractions were tested for virucidal, attachment, and viral protease inhibition. In virucidal activity assay (Figure 7(a)), $\mathrm{EA}$ and $\mathrm{BuOH}$ fractions at $100 \mu \mathrm{g} / \mathrm{mL}$ showed low virucidal activity for EV71 and CoxA16 (reduction less than 25\%). Eupafolin at 1 or $10 \mu \mathrm{g} / \mathrm{mL}$ reduced CoxA16 infectivity by $30 \%$, but slightly affected EV71 infectivity (lower than 20\%). In attachment inhibition assay (Figure 7(b)), only EA fraction at 10 or $100 \mu \mathrm{g} / \mathrm{mL}$ inhibited above $30 \%$ of EV71 binding to $\mathrm{RD}$ cells. In cell-based viral $2 \mathrm{~A}$ protease activity assay (Figure 8), EA and $\mathrm{BuOH}$ fractions at $10 \mu \mathrm{g} / \mathrm{mL}$ inhibited CoxA16 2A protease activity by over $30 \%$. Still, eupafolin had no significant inhibitory effect on EV71 and CoxA16 activity. Results show difference in direct-acting antiviral actions by KGS EA and $\mathrm{BuOH}$ fractions. Eupafolin had moderate virucidal effect against both enterovirus types.

3.5. Inhibition of Virus-Induced Proinflammatory Cytokines by Eupafolin. To examine effect of eupafolin on virusinduced proinflammatory cytokine expression further, relative IL- 6 and RANTES mRNA levels in virus-infected cells treated with/without eupafolin, IFN- $\alpha$, or EA fraction were derived by quantitative real-time PCR (Figure 9). Eupafolin at $1 \mu \mathrm{g} / \mathrm{mL}$ decreased virus-induced IL-6 and RANTES expression by more than 10-fold, suppressing proinflammatory cytokines induced by EV71 and CoxA16 better than KGS EA fraction $(10 \mu \mathrm{g} / \mathrm{mL})$ and IFN- $\alpha(100 \mathrm{U} / \mathrm{mL})$. Phosphorylation levels of cytokine induction-related proteins p38 MAPK, 


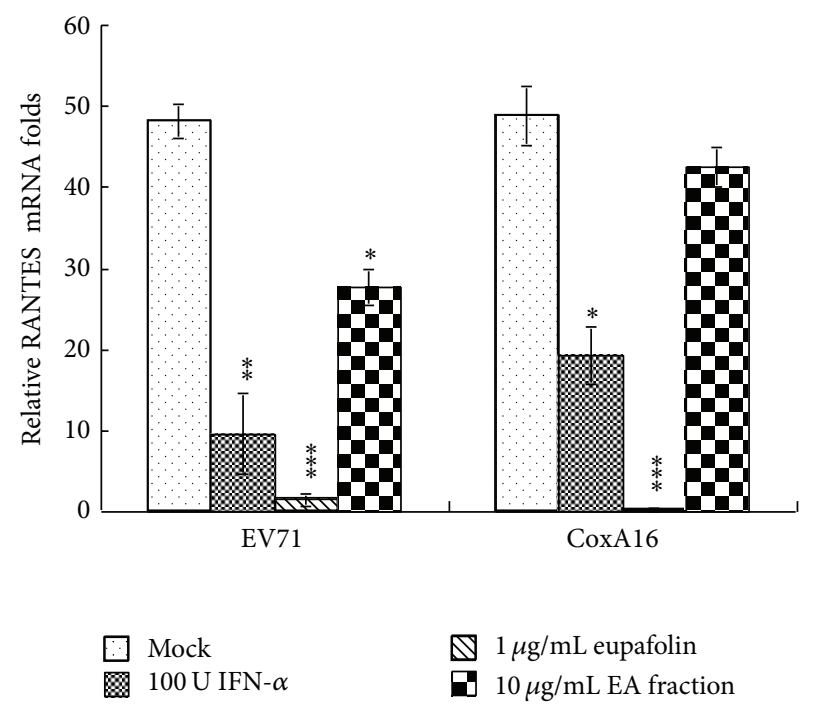

(a)

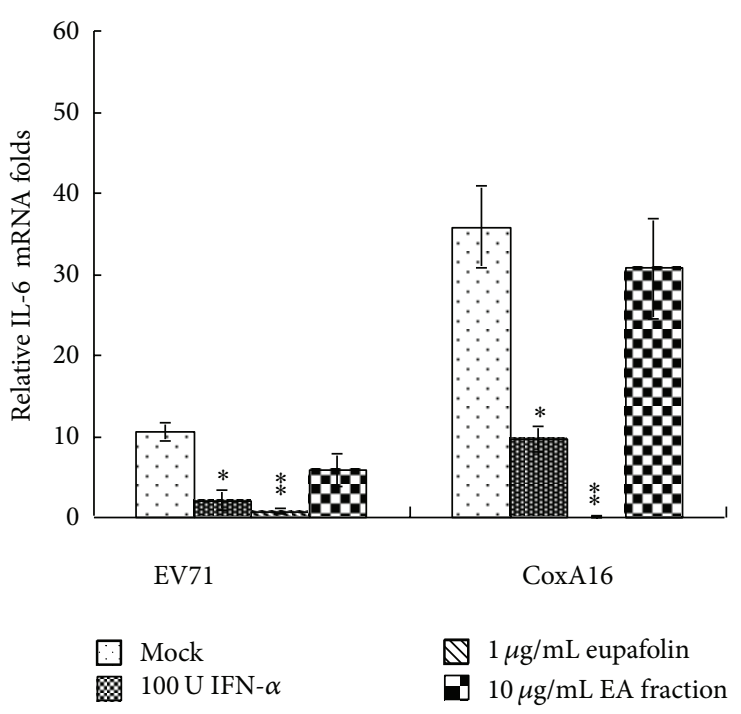

(b)

FIGURE 9: Expression levels of proinflammatory genes in infected RD cells treated with/without eupafolin and EA fraction. IL-6 (a) and RANTES (b) mRNA in RD cells $8 \mathrm{~h}$ postinfection and treatment were extracted and measured with real-time RT-PCR. Relative mRNA expression levels were normalized by housekeeping gene GAPDH. ${ }^{*} P$ value $<0.05 ;{ }^{* *} P$ value $<0.01 ;{ }^{* * *} P$ value $<0.001$ by Scheffe's test.

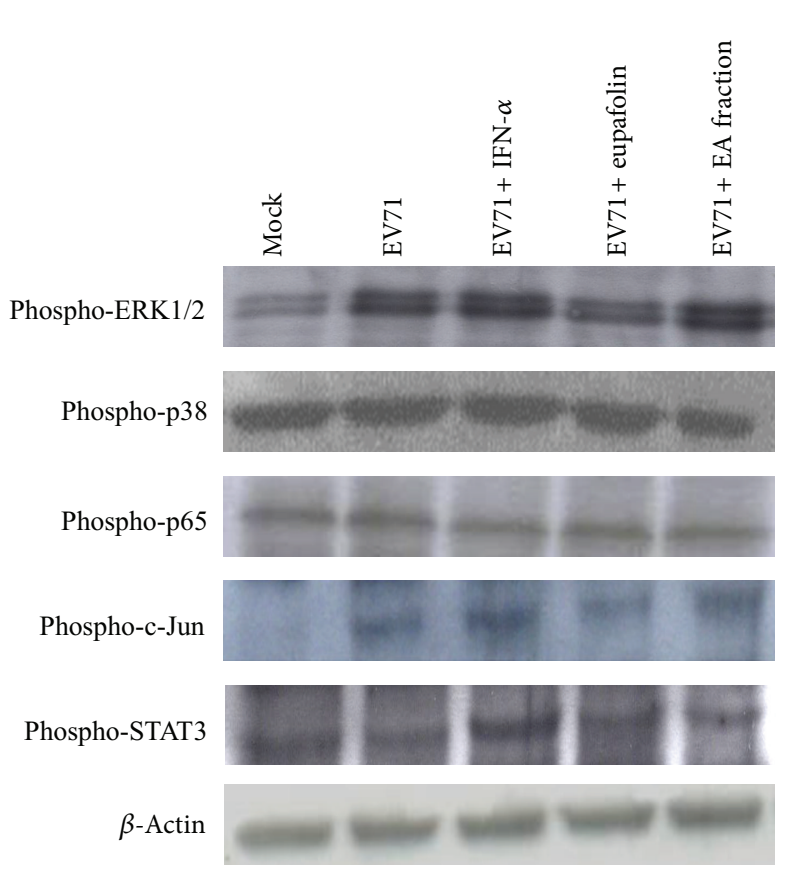

(a)

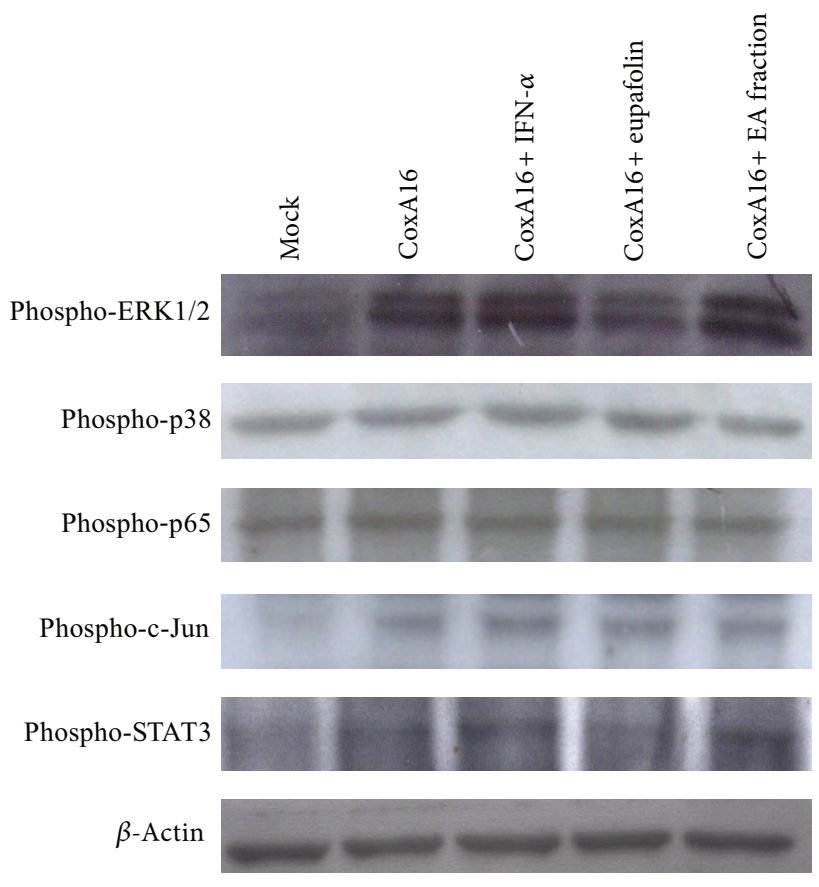

(b)

FIGURE 10: Phosphorylation levels of ERK1/2, p38 MAPK, p65 (NF- $\kappa$ B), c-Jun, and STAT3 in infected RD cells treated with(out) eupafolin and EA fraction. EV71 (a) or CoxA16 (b) infected RD cells were harvested $9 \mathrm{~h}$ posttreatment, and lysates resolved on $10 \%$ SDS-PAGE and transferred onto nitrocellulose paper. Blot was probed with specific mAbs, developed with alkaline phosphatase-conjugated secondary antibody and enhanced chemiluminescence substrates. Lane 1, mock cells; Lane 2, infected cells; Lane 3, infected cells treated with IFN- $\alpha$; Lane 4, infected cells treated with eupafolin; Lane 5, infected cells treated with EA fraction.

ERK1/2, NF- $\kappa$ B (p65), c-Jun, and STAT3 in virus-infected cells treated with or without eupafolin, IFN- $\alpha$, or EA fraction were subsequently analyzed by Western blotting via phosphorylation site-specific antibodies (Figure 10). EV71 and CoxA16 infections raised phosphorylation of ERK1/2, c-Jun, and STAT3, but not p38 MAPK and NF- $\kappa$ B p 65 , $9 \mathrm{~h}$ postinfection. Treatment with eupafolin attenuated activation of ERK1/2, c-Jun, and STAT3 in EV71- and CoxA16-infected cells. Data confirm eupafolin suppressing IL-6 and RANTES expressions and reducing ERK1/2, AP-1, and STAT3 mediated 
signaling induced by EV71 and CoxA16, suggesting antiinflammatory effect of eupafolin as involved in antiviral activity against EV71 and CoxA16.

\section{Discussion}

KGS extract, EA, and $\mathrm{BuOH}$ fractions, as well as its components eupafolin and caffeic acid, processed low cytotoxicity (Figure 1, Table 1). KGS EA fraction had an antienterovirus activity with $\mathrm{IC}_{50}$ values less $10 \mu \mathrm{g} / \mathrm{mL}$, more effectively inhibiting replication of EV71 and CoxA16 in vitro than KGS extract and $\mathrm{BuOH}$ fraction (Figures 2-4, Table 1). EA fraction contained antiviral components: eupafolin (3.10 \pm $0.09 \mu \mathrm{g} / \mathrm{mg}$ ) with $\mathrm{IC}_{50}$ values of $1.39 \mu \mathrm{M}$ for EV71 and $5.24 \mu \mathrm{M}$ for CoxA16, as well as caffeic acid $(10.91 \pm 0.31 \mu \mathrm{g} / \mathrm{mg})$ with $\mathrm{IC}_{50}$ values of $132.50 \mu \mathrm{M}$ for EV71 and $197.11 \mu \mathrm{M}$ for CoxA16 (Figures 5-6, Table 1). Our prior study proved quercetin an active antienterovirus component of $K$. gracilis leaf extract, showing $\mathrm{IC}_{50}$ values above $117 \mu \mathrm{M}$ for EV71 and $176 \mu \mathrm{M}$ for CoxA16 [14]. Eupafolin was thus suggested as crucially active antienterovirus component in K. gracilis, at the same time showing similar anti-EV71 efficacy and selectivity with identified potential anti-EV71 compounds of natural products like allophycocyanin, aloe-emodin, gallic acid, chrysosplenetin, and penduletin [17-20].

KGS extract reduced by more than $90 \%$ both cytopathicity and virus yield $36 \mathrm{~h}$ postinfection (Figure 2), implying antiviral activity linked with direct and indirect antiviral actions: for example, virucidal activity, attachment blocking, targeting viral enzymes, and host factors, inducing host antiviral responses. Our prior study [14] demonstrated $K$. gracilis leaf extract inhibiting viral 2A protease activity, reducing virus-induced apoptosis, as well as suppressing IL6 and RANTES upregulation by EV71 and CoxA16. This study averred both KGS fractions plus eupafolin exhibiting low virucidal activity and slightly blocking virus attachment (Figures 7(a)-7(b)). Both KGS fractions inhibited CoxA16 2A proteases of CoxA16, but eupafolin failed to inhibit viral $2 \mathrm{~A}$ proteases (Figure 8 ). Eupafolin specifically inhibited upregulation of IL-6 and RANTES gene expressions induced by EV71 or CVA16 infection (Figure 9), which correlated with reduction of virus-induced ERK1/2, c-Jun, and STAT3 mediated signaling (Figure 10). Both KGS fractions exhibited multiple inhibitory actions against EV71 and CoxA16, relating to decrease of viral infectivity, attachment, and protease enzymatic activity in vitro. Aside from virucidal activity and attachment inhibition, eupafolin significantly inhibited production of IL- 6 and RANTES in enterovirus infection. EV71-infected patients' elevated levels of IL-1 $\beta$, IL-6, and TNF- $\alpha$ in CSF strongly correlate with clinical severity [21, 22]. In addition, EV71 infection causes the upregulation of COX-2 and PGE(2) via activation of ERK1/2 and AP1 signaling pathways [23]. Eupafolin significantly inhibited activation of ERK1/2, c-Jun, and STAT3 in both virus-infected cells, which correlates with suppressing upregulation of IL6 and RANTES by eupafolin treatment. It thus processed potent antiviral and antiproinflammatory activities, displaying therapeutic potential against EV71 and CoxA16 infection. Combination of effective compounds of K. gracilis, including eupafolin, quercetin, and caffeic acid, could provide an alternative approach against enteroviral infection.

In sum, KGS extract contains potent antienteroviral components; fractionation augments antienteroviral effect. Eupafolin, a crucial antiviral component of KGS EA fraction, shows high selective index for EV71 and CoxA16 by greater than a 30 -fold increase. Eupafolin is the potential enteroviral agent with anti-inflammatory activities via suppressing virusinduced activation of ERK1/2, AP-1, and STAT3-mediated signaling pathways.

\section{Conflict of Interests}

The authors declare no conflict of interests.

\section{Acknowledgments}

This project was funded by Grants from China Medical University (CMU99-NSC-08, CMU101-ASIA-05, CMU101-S24, and CMU100-S-33) and the Republic of China National Science Council (NSC101-2320-B-039-036-MY3, NSC 992628-B-039-006-MY3).

\section{References}

[1] S. A. Sanders, L. J. Herrero, K. McPhie et al., "Molecular epidemiology of enterovirus 71 over two decades in an Australian urban community," Archives of Virology, vol. 151, no. 5, pp. 10031013, 2006.

[2] S. Singh, V. T. K. Chow, M. C. Phoon, K. P. Chan, and C. L. Poh, "Direct detection of enterovirus 71 (EV71) in clinical specimens from a hand, foot, and mouth disease outbreak in Singapore by reverse transcription-PCR with universal enterovirus and EV71-specific primers," Journal of Clinical Microbiology, vol. 40, no. 8, pp. 2823-2827, 2002.

[3] Y. Ishimaru, S. Nakano, K. Yamaoka, and S. Takami, "Outbreaks of hand, foot, and mouth disease by enterovirus 71. High incidence of complication disorders of central nervous system," Archives of Disease in Childhood, vol. 55, no. 8, pp. 583-588, 1980.

[4] M. A. Pallansch and R. P. Roos, "Enteroviruses: polioviruses, coxsackieviruses, echoviruses, and newer enteroviruses," in Fields Virology, D. N. Knipe, P. M. Howley, D. E. Griffin et al., Eds., pp. 839-894, 5th edition, 2007.

[5] Z. Fan, A. O. Yalcin, F. D. Tichelaar et al., "From sphere to multipod: thermally induced transitions of cdse nanocrystals studied by molecular dynamics simulations," Journal of the American Chemical Society, vol. 135, Article ID ja401406q, 8 pages, 2013.

[6] X.-F. Yan, S. Gao, J.-F. Xia, R. Ye, H. Yu, and J.-E. Long, "Epidemic characteristics of hand, foot, and mouth disease in Shanghai from 2009 to 2010: enterovirus 71 subgenotype C4 as the primary causative agent and a high incidence of mixed infections with coxsackievirus A16," Scandinavian Journal of Infectious Diseases, vol. 44, no. 4, pp. 297-305, 2012.

[7] V. Gopalkrishna, P. R. Patil, G. P. Patil, and S. D. Chitambar, "Circulation of multiple enterovirus serotypes causing hand, foot and mouth disease in India," Journal of Medical Microbiology, vol. 61, no. 3, pp. 420-425, 2012.

[8] M. C. Kao, Handbook of Taiwan Medicinal Plants, Southern Materials Center, Taiwan, 1981. 
[9] Z.-R. Lai, W.-H. Peng, Y.-L. Ho et al., "Analgesic and antiinflammatory activities of the methanol extract of kalanchoe gracilis (L.) DC stem in mice," American Journal of Chinese Medicine, vol. 38, no. 3, pp. 529-546, 2010.

[10] Z.-R. Lai, Y.-L. Ho, S.-C. Huang et al., "Antioxidant, anti-inflammatory and antiproliferative activities of kalanchoe gracilis (L.) DC stem," American Journal of Chinese Medicine, vol. 39, no. 6, pp. 1275-1290, 2011.

[11] M. Maas, A. M. Deters, and A. Hensel, "Anti-inflammatory activity of Eupatorium perfoliatum L. extracts, eupafolin, and dimeric guaianolide via iNOS inhibitory activity and modulation of inflammation-related cytokines and chemokines," Journal of Ethnopharmacology, vol. 137, no. 1, pp. 371-381, 2011.

[12] A. Hensel, M. Maas, J. Sendker et al., "Eupatorium perfoliatum L.: phytochemistry, traditional use and current applications," Journal of Ethnopharmacology, vol. 138, no. 3, pp. 641-651, 2011.

[13] K.-S. Chung, J.-H. Choi, N.-I. Back et al., "Eupafolin, a flavonoid isolated from Artemisia princeps, induced apoptosis in human cervical adenocarcinoma HeLa cells," Molecular Nutrition and Food Research, vol. 54, no. 9, pp. 1318-1328, 2010.

[14] C. Y. Wang, S. C. Huang, Y. Zhang et al., "Antiviral ability of Kalanchoe gracilis leaf extract against enterovirus 71 and coxsackievirus A16," Evidence-Based Complementary and Alternative Medicine, vol. 2012, Article ID 503165, 13 pages, 2012.

[15] M. M. Salama, Z. A. Kandil, and W. T. Islam, "Cytotoxic compounds from the leaves of Gaillardia aristata pursh. growing in Egypt," Natural Product Research, vol. 26, no. 22, pp. 2057-2062, 2012.

[16] M.-T. Tsai, Y.-H. Cheng, Y.-N. Liu, N.-C. Liao, W.-W. Lu, and S.-H. Kung, "Real-time monitoring of human enterovirus (HEV)-infected cells and anti-HEV 3C protease potency by fluorescence resonance energy transfer," Antimicrobial Agents and Chemotherapy, vol. 53, no. 2, pp. 748-755, 2009.

[17] C.-W. Lin, C.-F. Wu, N.-W. Hsiao et al., "Aloe-emodin is an interferon-inducing agent with antiviral activity against Japanese encephalitis virus and enterovirus 71," International Journal of Antimicrobial Agents, vol. 32, no. 4, pp. 355-359, 2008.

[18] S.-R. Shih, K.-N. Tsai, Y.-S. Li, C.-C. Chueh, and E.-C. Chan, "Inhibition of enterovirus 71-induced apoptosis by allophycocyanin isolated from a blue-green alga Spirulina platensis," Journal of Medical Virology, vol. 70, no. 1, pp. 119-125, 2003.

[19] H. J. Choi, J. H. Song, K. S. Park, and S. H. Baek, "In vitro antienterovirus 71 activity of gallic acid from Woodfordia fruticosa flowers," Letters in Applied Microbiology, vol. 50, no. 4, pp. 438440, 2010.

[20] Q.-C. Zhu, Y. Wang, Y.-P. Liu et al., "Inhibition of enterovirus 71 replication by chrysosplenetin and penduletin," European Journal of Pharmaceutical Sciences, vol. 44, no. 3, pp. 392-398, 2011.

[21] X. Gong, J. Zhou, W. Zhu et al., "Excessive proinflammatory cytokine and chemokine responses of human monocytederived macrophages to enterovirus 71 infection," BMC Infectious Diseases, vol. 12, article 224, 9 pages, 2012.

[22] C. C. Lien and Y. M. Trai, "Enterovirus 71 infection of human immune cells induces the production of proinflammatory cytokines," Journal of Biomedical Sciencr, vol. 12, no. 3, pp. 8290, 2009.

[23] W.-H. Tung, I.-T. Lee, H.-L. Hsieh, and C.-M. Yang, "EV71 induces COX-2 expression via c-Src/PDGFR/PI3K/Akt/p42/ p44 MAPK/AP-1 and NF- $\kappa$ B in rat brain astrocytes," Journal of Cellular Physiology, vol. 224, no. 2, pp. 376-386, 2010. 


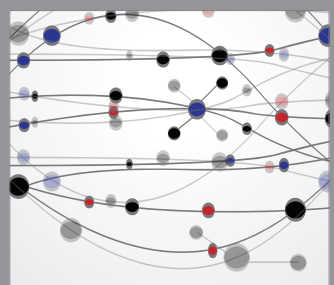

The Scientific World Journal
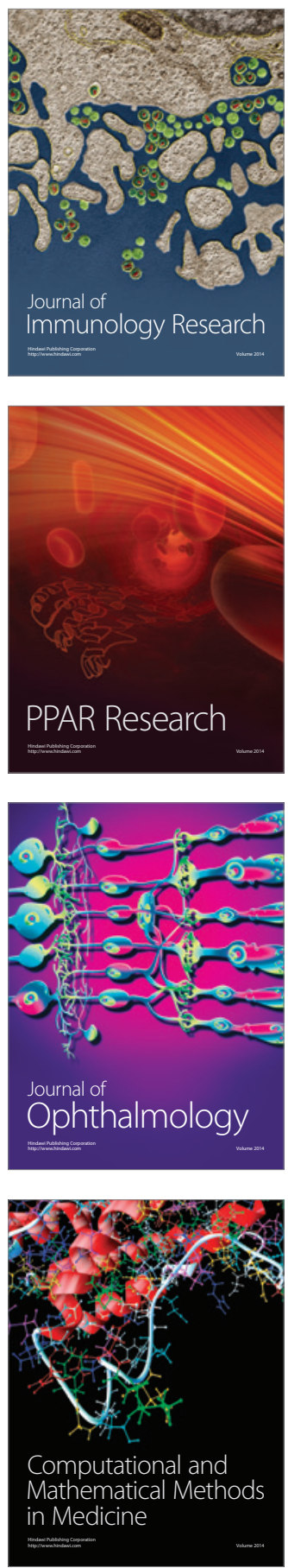

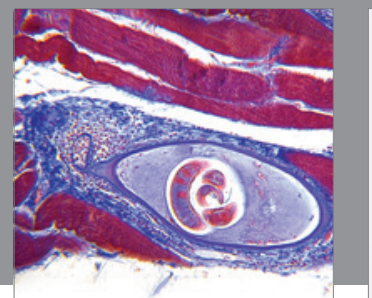

Gastroenterology

Research and Practice
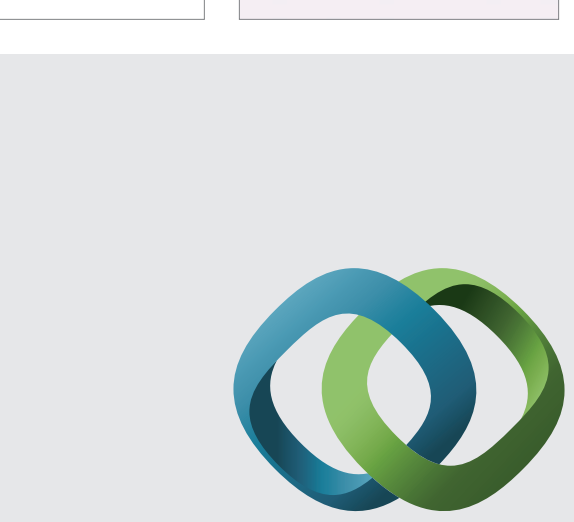

\section{Hindawi}

Submit your manuscripts at

http://www.hindawi.com
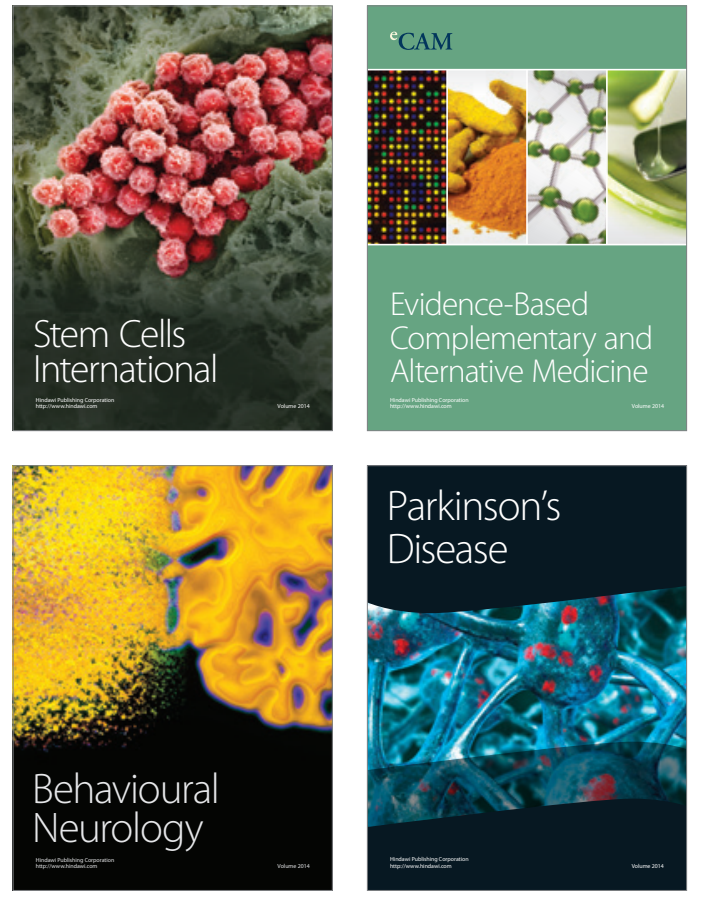
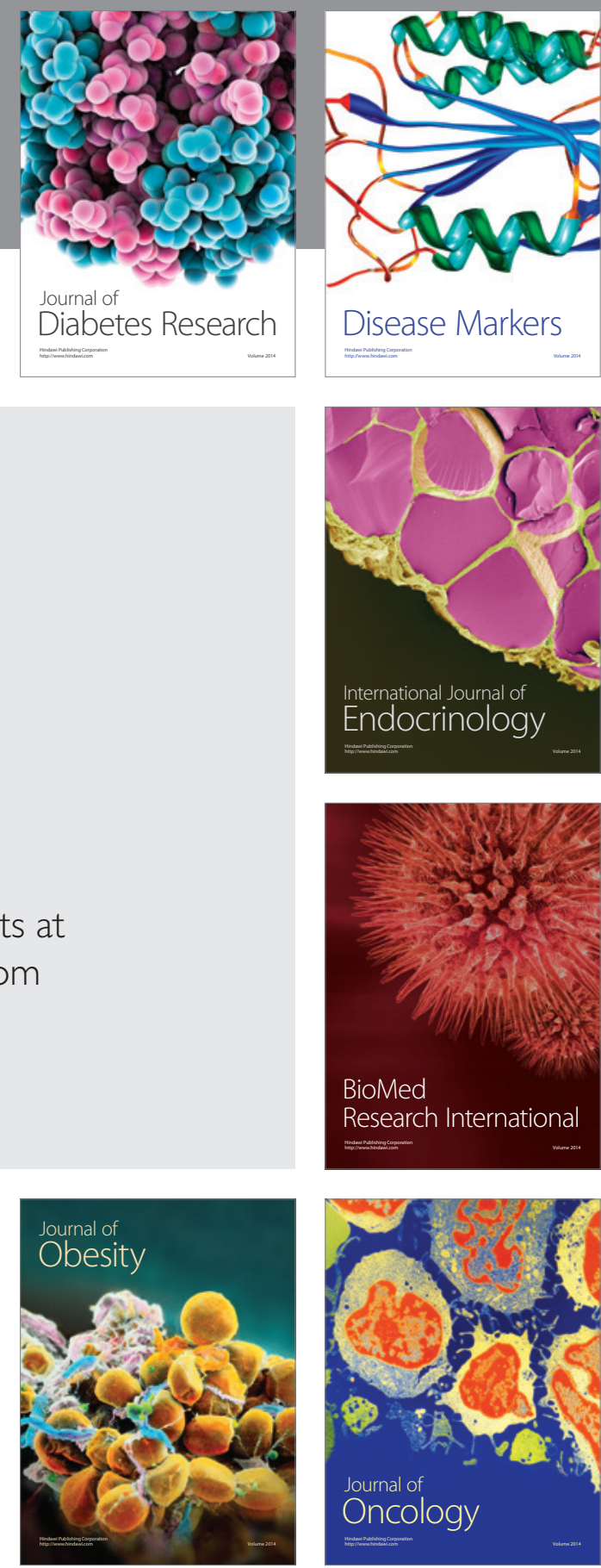

Disease Markers
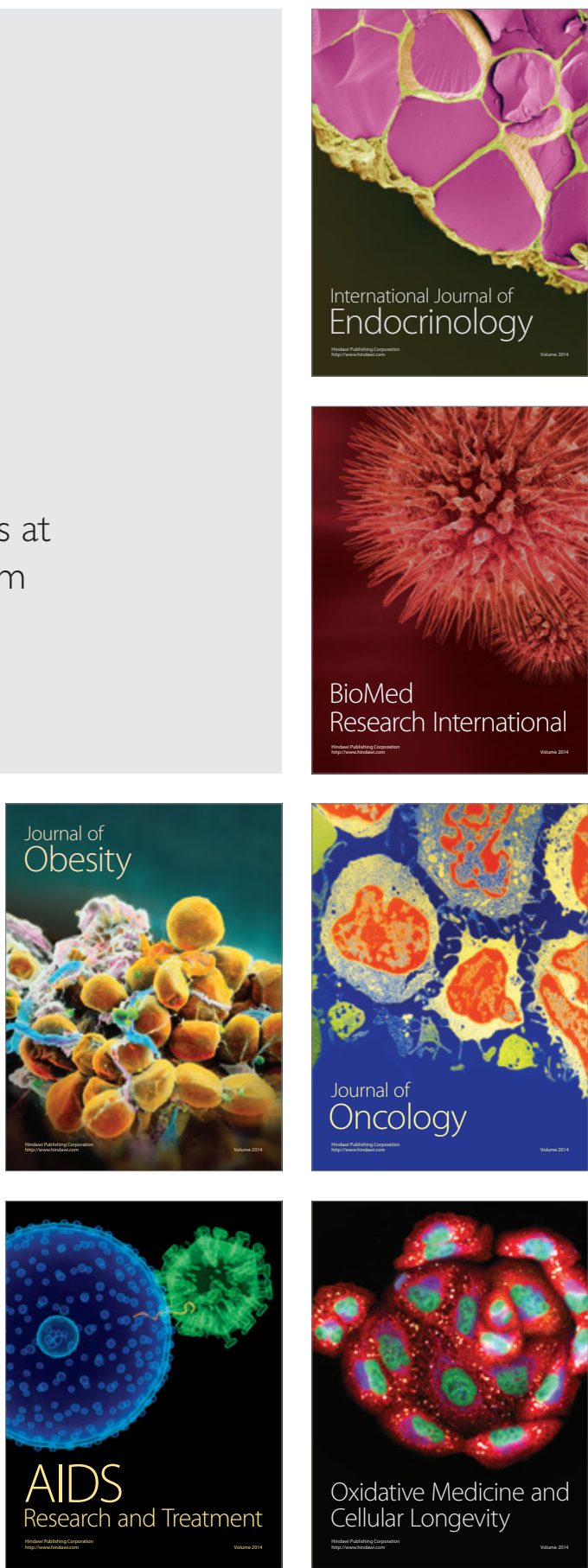